\title{
Determination of RKI-1447 in Rat Plasma by UPLC-MS/MS and Investigation on Its Pharmacokinetics, an Effective ROCK1 and ROCK2 Inhibitor
}

\author{
Yue Luo ${ }^{1}$, Liyi $\mathrm{Li}^{1}$, Jinzhang Cai ${ }^{1}$, Jianshe $\mathrm{Ma}^{2}$, Le Liu ${ }^{3}$, Xianqin Wang ${ }^{2 *}$ and Chun $\mathrm{Jin}^{3 *}$ \\ ${ }^{1}$ The Second Affiliated Hospital and Yuying Children's Hospital, Wenzhou Medical University, Wenzhou 325000, China \\ ${ }^{2}$ Analytical and Testing Center, School of Pharmaceutical Sciences, Wenzhou Medical University, Wenzhou 325035, China \\ ${ }^{3}$ The First Affiliated Hospital of Wenzhou Medical University, Wenzhou 325000, China
}

Received: 02 March 2018; accepted: 19 April 2018

\begin{abstract}
RKI-1447 is an effective ROCK1 and ROCK2 inhibitor, having anti-invasion and anti-tumor activity. In this study, we used ultra-performance liquid chromatography-tandem mass spectrometry (UPLC-MS/MS) to detect RKI-1447 in rat plasma and investigated its pharmacokinetics in rats. Diazepam was utilized as an internal standard, and an acetonitrile precipitation method was used to process the plasma samples. Chromatographic separation was achieved using a UPLC ethylene bridged hybrid (BEH) column $(2.1 \mathrm{~mm} \times 50 \mathrm{~mm}, 1.7 \mu \mathrm{m})$ with a gradient acetonitrile-water mobile phase (containing $0.1 \%$ formic acid). Flow rate was set at $0.4 \mathrm{~mL} / \mathrm{min}$. Electrospray ionization (ESI)-tandem mass spectrometry in multiple reaction monitoring (MRM) mode with positive ionization was applied: $\mathrm{m} / \mathrm{z} 327.1 \rightarrow 204.0$ and $285.1 \rightarrow 193.3$ for RKI-1447 and internal standard, respectively. The results indicated that within the range of $10-2000 \mathrm{ng} / \mathrm{mL}$, the linearity of RKI-1447 in rat plasma was acceptable $(\mathrm{r}>0.995)$, and the lowest limit of quantification (LLOQ) was $10 \mathrm{ng} / \mathrm{mL}$. Intra-day precision RSD of RKI-1447 in rat plasma was lower than 8\%, and inter-day precision RSD was lower than $11 \%$. Accuracy range was between $91.6 \%$ and $107.1 \%$, and the matrix effect was between $85.1 \%$ and $87.0 \%$. The analysis method was sensitive and fast with suitable selectivity, and was successfully applied in the pharmacokinetics of RKI-1447 in rats. The bioavailability of the RKI-1447 was 7.3\%.
\end{abstract}

Keywords: RKI-1447, pharmacokinetics, bioavailability, rat, UPLC-MS/MS

\section{Introduction}

Ever since Clark et al. discovered that invasion and metastasis of melanoma closely correlated with Ras homolog (Rho)-associated coiled-coil-forming protein kinase (ROCK) signal transduction pathway, there have been continuous reports on the close correlation between Ras homolog family member $\mathrm{C}$ (RhoC) in this signal pathway and invasion and metastasis of tumor cells [1]. This signal pathway has three critical signal molecules: RhoGTP enzyme, ROCK, and myosin phosphatase.

The imbalance of Rho-ROCK signal transduction pathway can cause metastasis of malignant tumor [2]. The activation of ROCK and phosphorylation of myosin light chain 2 (MLC-2) are closely associated with malignant tumor. The firmness of adherens junction among tumor cells depends on the phosphorylation level of MLC-2 It can directly regulate contractile activity of cells and further control the malignant activity of cells [3].

Rho-ROCK inhibitor RKI-1447 was found by Patel et al., and they proved that RKI-1447 was a powerful small-molecule inhibitor specific to ROCK1 and ROCK2. The study indicated that it mainly prevented cytoskeletal protein from shrinking and inhibited migration and invasion of breast cancer cells by inhibiting phosphorylation of MLC protein in the downstream of Rho-ROCK signal pathway [4].

Pharmacokinetics is a discipline that quantitatively investigates the absorption, distribution, and excretion of drug in vivo $[5,6]$. In order to learn more about the absorption and distribution of RKI-1447 in vivo, it is necessary to systematically investigate its pharmacokinetics, which provides theoretical basis for drug research and development. Accordingly, a detection method for

\footnotetext{
* Authors for correspondence: lankywang@163.com (X.W.); 280691887@ qq.com (C.J.)
}

RKI-1447 in plasma should be established, based on which the pharmacokinetics characteristics will be investigated.

So far, no analytical method has been found on the detection of RKI-1447 in plasma and its pharmacokinetics. Compared to liquid chromatography-tandem mass spectrometry (LC-MS/MS), ultraperformance liquid chromatography-MS/MS (UPLC-MS/MS) is more sensitive, possessing significant advantages in the investigation on pharmacokinetics of drugs. Meanwhile, the powerful separation and analysis capacity are applicable to analyze the in vivo metabolism of complex compound systems [7-10]. In this study, we established an analysis method for RKI-1447 in rat plasma, detected the drug in plasma that was administrated via different routes, and investigated its pharmacokinetics in rats. The bioavailability of RKI-1447 was then calculated, providing scientific basis for clinical application.

\section{Materials and Methods}

Experimental Materials. RKI-1447 (purity $>98 \%$, Figure 1A) was purchased from Selleck Chemicals (Texas, USA). Diazepam (internal standard (IS), purity $>98 \%$, Figure 1B) was obtained from National Institutes for Food and Drug Control (Beijing, China). High-performance liquid chromatography (HPLC)-grade acetonitrile and methanol were purchased from Merck (Darmstadt, Germany). HPLC-grade formic acid was obtained from Tedia (Ohio, USA). Ultrapure water was prepared using a Millipore Milli-Q water system (Bedford, MA, USA). Sprague Dawley (SD) rats (male; body weight: 200-220 g) were obtained from Animal Experimental Center of Wenzhou Medical University.

Equipment. ACQUITY I-Class UPLC and XEVO TQ-S micro triple quadrupole mass spectrometer (Waters Corp, Milford, MA, USA) were used in this study. Masslynx 4.1 software (Waters Corp.) was used to collect data and control the equipment.

This is an open-access article distributed under the terms of the Creative Commons Attribution-NonCommercial 4.0 International License (https://creativecommons.org/licenses/by-nc/4.0/), which permits unrestricted use, distribution, and reproduction in any medium for non-commercial purposes, provided the original author and source are credited, a link to the CC License is provided, and changes - if any - are indicated. 
<smiles>O=C(NCc1cccc(O)c1)Nc1nc(-c2ccncc2)cs1</smiles>

(A)<smiles>CN1C(=O)CN=C(c2ccccc2)c2cc(Cl)ccc21</smiles>

(B)

Figure 1. Chemical structure of (A) RKI-1447 and (B) diazepam

UPLC ethylene bridged hybrid $(\mathrm{BEH}) \mathrm{C} 18(2.1 \mathrm{~mm} \times 50 \mathrm{~mm}$, $1.7 \mu \mathrm{m})$ was used at a temperature of $40{ }^{\circ} \mathrm{C}$. The mobile phase was composed of acetonitrile and water (containing $0.1 \%$ formic acid) in gradient elute, and the flow rate was set at $0.4 \mathrm{~mL} / \mathrm{min}$.
The gradient elution was as follows: $0-0.2 \mathrm{~min}$, acetonitrile $10 \%$; 0.2-1.5 min, linear acetonitrile from $10 \%$ to $80 \% ; 1.5-2.0 \mathrm{~min}$, acetonitrile $80 \% ; 2.0-2.5 \mathrm{~min}$, linear acetonitrile from $80 \%$ to $10 \%$; and $2.5-4.0 \mathrm{~min}$, acetonitrile $10 \%$. The total run time was $4.0 \mathrm{~min}$. Acetonitrile-water $(10 / 90, v / v)$ was used for wash solution.

Nitrogen was used as desolvation gas $(900 \mathrm{~L} / \mathrm{h})$ and nebulising gas. Capillary voltage was set at $2.6 \mathrm{kV}$, ion source temperature was $150^{\circ} \mathrm{C}$, and desolvation temperature was $450{ }^{\circ} \mathrm{C}$. As shown in Figure 2, electrospray ionization (ESI)-tandem mass spectrometry in the multiple reaction monitoring (MRM) mode with positive ionization was used: $m / z 327.1 \rightarrow 204.0$ (cone voltage of $30 \mathrm{~V}$ and fragmentor voltage of $25 \mathrm{~V}$ ) and $285.1 \rightarrow$ 193.3 (cone voltage of $45 \mathrm{~V}$ and fragmentor voltage of $36 \mathrm{~V}$ ) for RKI-1447 and internal standard, respectively.

Preparation for Control Solutions. Methanol was used to prepare stock solutions of RKI-1447 $(1.0 \mathrm{mg} / \mathrm{mL})$ and diazepam $(1.0 \mathrm{mg} / \mathrm{mL})$. RKI-1447 standard solutions with different concentrations were prepared by diluting the stock solutions with acetonitrile. Diazepam at a concentration of $50 \mathrm{ng} / \mathrm{mL}$ was diluted with acetonitrile from diazepam stock solution. All of the solutions were stored at $4{ }^{\circ} \mathrm{C}$.

Preparation for Standard Curve. The blank rat plasma was spiked with moderate amounts of working solutions of RKI-1447 to prepare standard solutions with concentrations of $10,20,50$, $100,200,500,1000$, and $2000 \mathrm{ng} / \mathrm{mL}$ (concentration range within $10-2000 \mathrm{ng} / \mathrm{mL}$ ). Quality control samples at concentrations of 30,450 , and $1800 \mathrm{ng} / \mathrm{mL}$ were prepared using the same method.

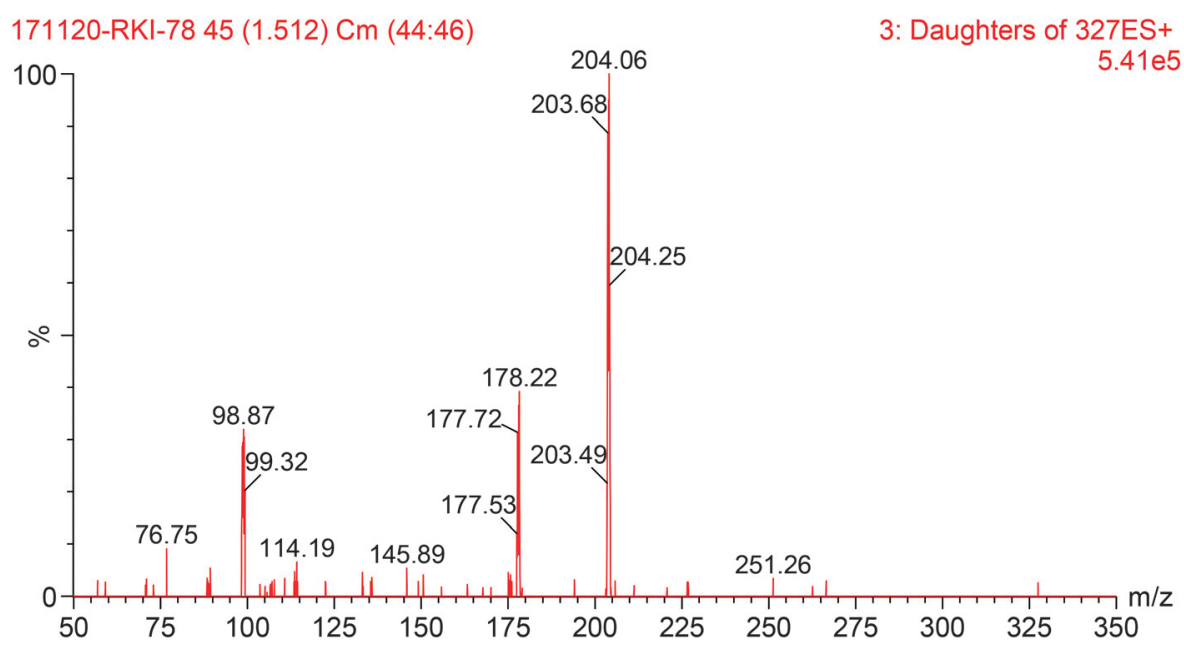

(A)

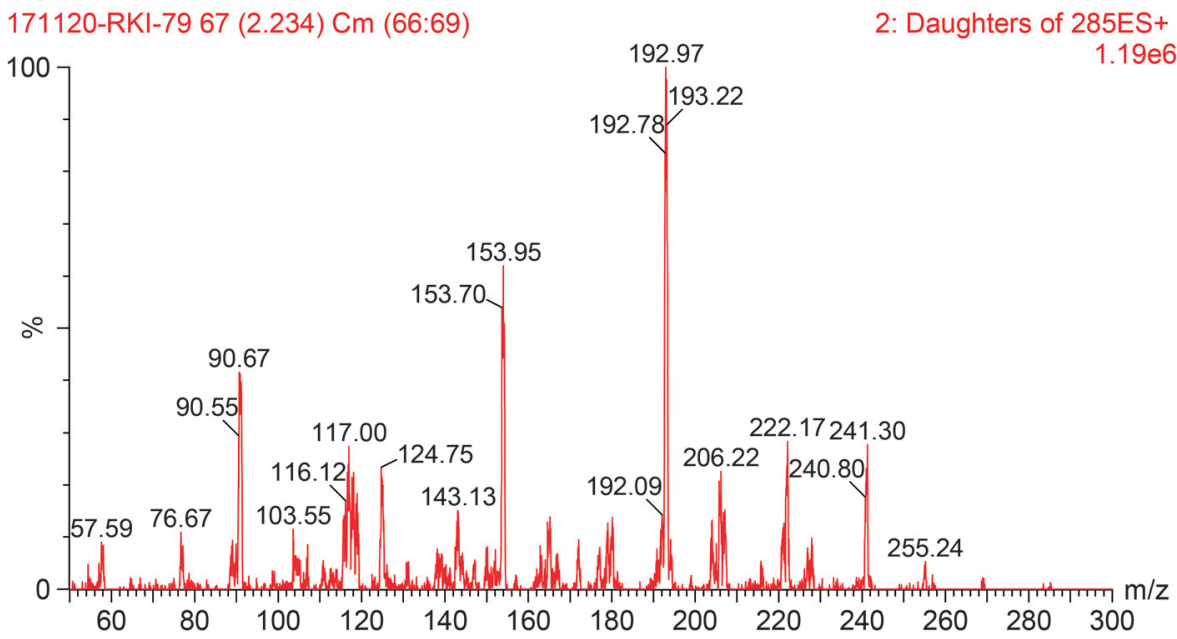

(B)

Figure 2. Mass spectra of (A) RKI-1447 and (B) diazepam 


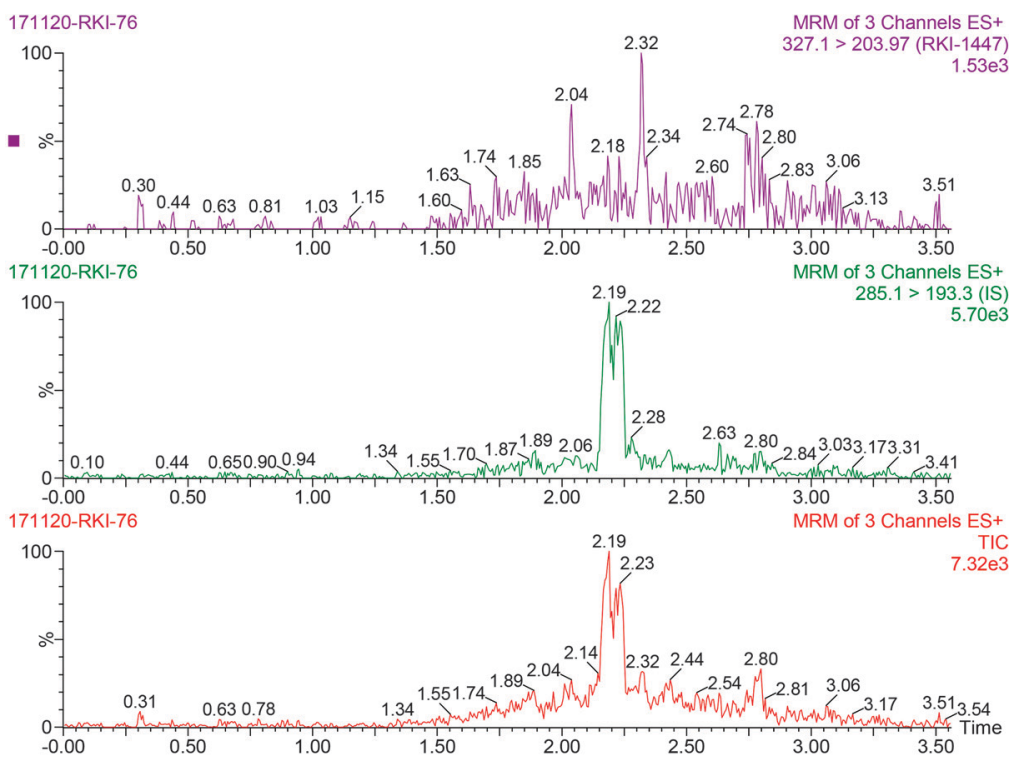

(A)

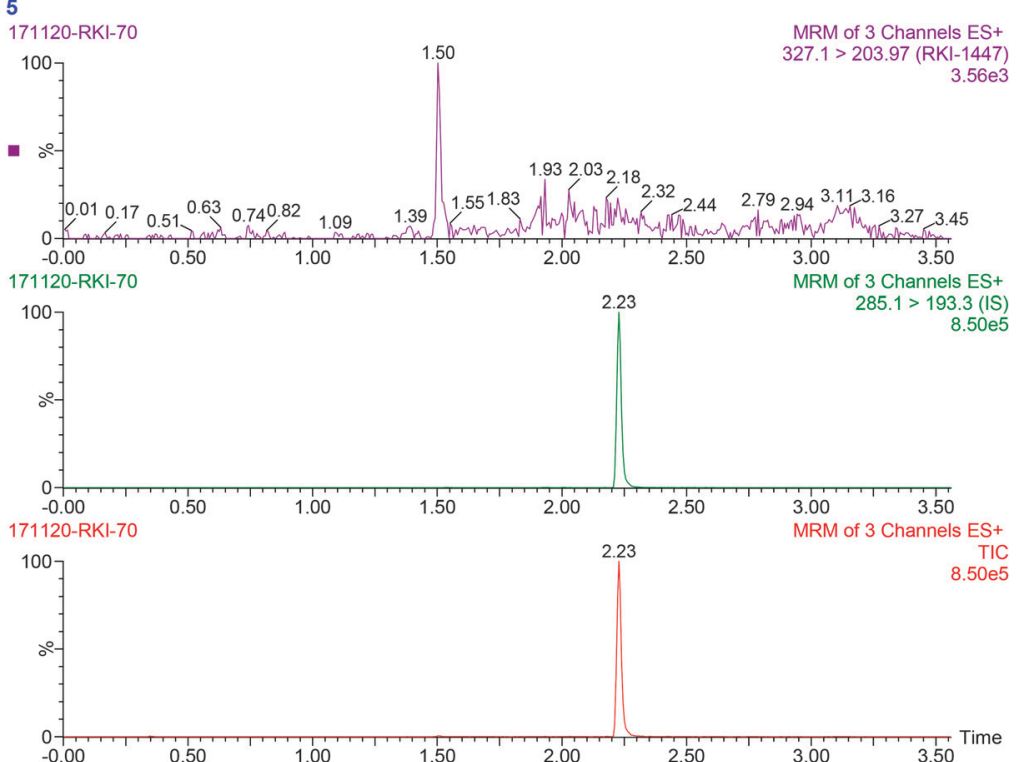

(B)

7

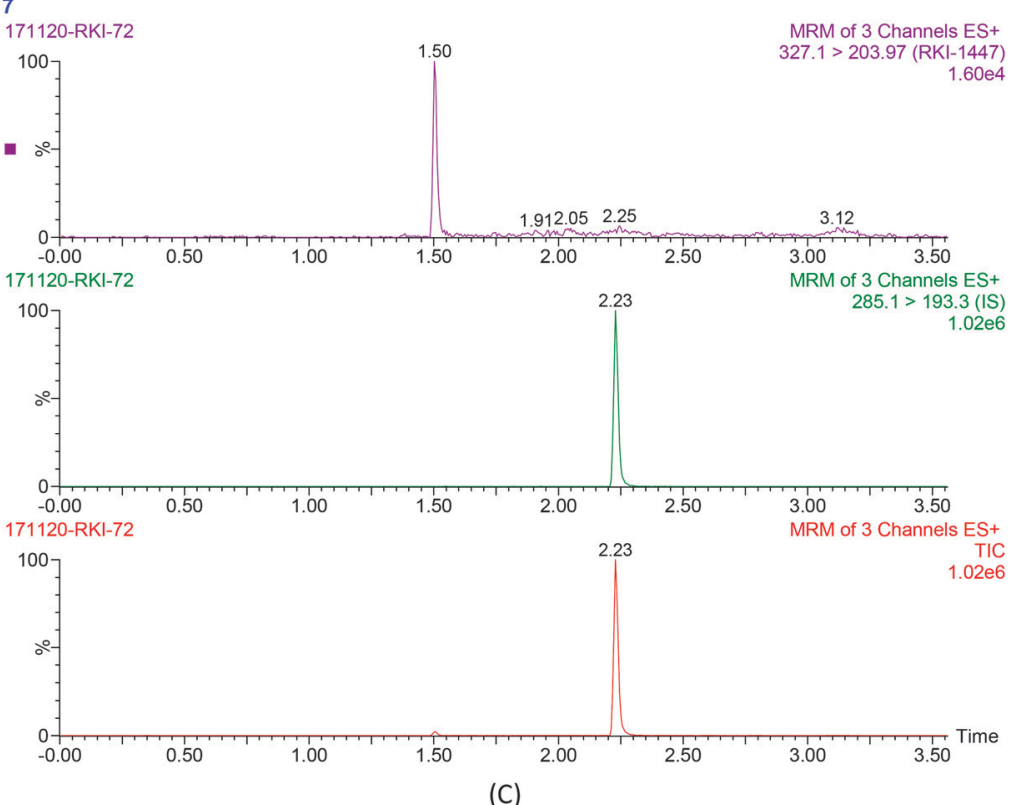

Figure 3. UPLC-MS/MS spectra of RKI-1447 and diazepam (internal standard) in rat plasma. (A) blank plasma, (B) blank plasma spiked with RKI-1447 (10 ng/mL) and internal standard (50 ng/mL), and (C) RKI-1447 in plasma $1 \mathrm{~h}$ after intravenous administration 
Plasma Processing. In a $1.5 \mathrm{~mL}$ Eppendorf (EP) tube, $50 \mu \mathrm{L}$ plasma was added, further diluted with acetonitrile $(150 \mu \mathrm{L}$, containing internal standard diazepam $50 \mathrm{ng} / \mathrm{mL}$ ), mixed by a vortexer for $1.0 \mathrm{~min}$, and centrifuged at 13,000 rpm (Eppendorf Centrifuge 5810R, Hamburg, Germany) for $10 \mathrm{~min}$ at $4{ }^{\circ} \mathrm{C}$. The supernate $(100 \mu \mathrm{L})$ was transferred into a liner pipe in a vial, and the injection volume was set at $2 \mu \mathrm{L}$.

Method Validation. To explore whether endogenous substance would interfere with detection of the compound and the internal standard, blank rat plasma samples from 6 different rats and lowest-limit-of-quantification (LLOQ) samples prepared with corresponding blank rat plasma were detected by UPLC-MS/MS. The detected concentration of LLOQ should be the baseline value of blank plasma plus concentration of added RKI-1447, and the deviation should be within $\pm 20 \%$.

Eight detected concentrations (10-2000 ng/mL) were used as $x$-axis, and the peak area ratio of the sample to internal standard was used as $y$-axis. Standard curve (linear regression equation) was obtained by weighted least-squares method $\left(W=1 / x^{2}\right)$.

Quality-control (QC) samples at low, medium, and high concentrations $(30,450$, and $1800 \mathrm{ng} / \mathrm{mL}$ ) were detected 6 times within 3 days. Intra- and inter-day precision and accuracy were calculated according to the concentrations of QC samples calculated by the intraday standard curve.

Recovery was assessed by the comparison of peak areas between the QC samples (at the 3 concentrations) and the standard samples. By spiking standard solutions into processed blank plasma, 3 solutions with low, medium, and high concentrations $(30,450$, and $1800 \mathrm{ng} / \mathrm{mL})$ were prepared. The matrix effect was evaluated by comparing between detected peak areas of the 3 solutions and those of the standard solutions (30, 450, and $1800 \mathrm{ng} / \mathrm{mL}$ ) diluted with acetonitrile- $0.1 \%$ formic acid $(1: 1, v / v)$.

Carry-over was assessed following injection of a blank plasma sample immediately after 3 repeats of the upper limit of quantification (ULOQ), after which the response was checked for accuracy $[11,12]$.

The stability of RKI-1447 was detected in the spiked plasma samples that were placed at room temperature for $6 \mathrm{~h}$, processed by protein precipitation and placed at room temperature for $12 \mathrm{~h}$, frozen-thawed 3 times, and placed at $-70{ }^{\circ} \mathrm{C}$ for 30 days.

Pharmacokinetics. RKI-1447, $30.0 \mathrm{mg}$, was accurately weighted and dissolved in DMSO to prepare a $2.0 \mathrm{mg} / \mathrm{mL}$ solution. The solution should be freshly prepared before the experiment. Twelve rats were randomly divided into 2 groups. The Ethics Committee permission number was Wydw 20130071. One group was given RKI-1447 $(10 \mathrm{mg} / \mathrm{kg})$ by oral (PO), and the other group was given RKI-1447 (2 mg/kg) by sublingual vein (IV), 6 rats for each group. Blood $(200 \mu \mathrm{L})$ was withdrawn from the caudal vein $5 \mathrm{~min}, 0.5 \mathrm{~h}, 1.5 \mathrm{~h}, 2 \mathrm{~h}$, $3 \mathrm{~h}, 4 \mathrm{~h}, 8 \mathrm{~h}$, and $12 \mathrm{~h}$ after administration and collected into $1.5 \mathrm{~mL}$ centrifuge tubes containing heparin. Plasma $(50 \mu \mathrm{L})$ was collected after centrifugation at $3000 \mathrm{rpm}$ for $10 \mathrm{~min}$ and stored at $-20{ }^{\circ} \mathrm{C}$.

Based on which bioavailability was calculated, the area under the curve (AUC), mean residence time (MRT), clearance rate $(\mathrm{CL})$, apparent distribution volume $(V)$, maximum plasma concentration $\left(C_{\max }\right)$, and half-life $\left(t_{1 / 2}\right)$ were all analyzed using DAS 2.0 software (China Pharmaceutical University).

\section{Results and Discussion}

Method Optimization. ESI-mass-spectrometry positivenegative selection is often evaluated in the methodology [13-18]. It has been found that the ESI positive ion mode is more sensitive than the negative ion mode. We optimized ionization of RKI-1447 and found that fragment ion $\mathrm{m} / \mathrm{z} 204.0$ had the highest abundance. The fragment ion $\mathrm{m} / \mathrm{z} 193.0$ from the internal standard had the highest abundance (Figure 2). Therefore, RKI-1447 m/z $327.1 \rightarrow$ 204.0 (cone voltage of $30 \mathrm{~V}$ and fragmentor voltage of $25 \mathrm{~V}$ ) and internal standard $\mathrm{m} / \mathrm{z} 285.1 \rightarrow 193.3$ (cone voltage of $45 \mathrm{~V}$ and fragmentor voltage of $36 \mathrm{~V}$ ) were used for quantitative analysis.

The HPLC condition should separate endogenous substances from analyte and internal standard in retention time as much as possible. Columns and mobile phase play a decisive role in chromatographic behavior $[19,20]$. We tried acetonitrile- $0.1 \%$ formic acid and methanol- $0.1 \%$ formic acid using the BEH C18 $(2.1 \mathrm{~mm} \times 50 \mathrm{~mm}, 1.7 \mu \mathrm{m})$ column. Suitable chromatographic peak and retention time could be obtained by using acetonitrile $-0.1 \%$ formic acid as the mobile phase. Compared with methanol, acetonitrile was more appropriate as an organic phase for the retention time of RKI-1447 and exhibited better peak shape. The system pressure of UPLC was smaller. Under the conditions of acetonitrile- $0.1 \%$ formic acid, the retention times of RKI-1447 and internal standard were $1.50 \mathrm{~min}$ and $2.23 \mathrm{~min}$, respectively.

The selection of internal standard is also important during method development [21, 22]. Here, diazepam was used as the internal standard of RKI-1447, and the extraction recovery and mass spectrometry ionization were similar to RKI-1447; therefore, it could be used as internal standard.

Method Validation. There were no obvious impurities and endogenous substances that had intervened in the detection of RKI-1447, suggesting that the selectivity of the method was acceptable. Figure 3 illustrates the UPLC-MS/MS chromatograms of blank plasma samples, blank plasma samples spiked with RKI-1447 and internal standard, and a plasma sample.

The concentrations of RKI-1447 standard curve in rat plasma were within the range of $10-2000 \mathrm{ng} / \mathrm{mL}$. The equation of standard curve is $y=0.000071068 x+0.000263952, r=0.9986$, where $y$ is the peak area ratio of RKI-1447 to internal standard and $x$ represents the RKI-1447 concentrations in plasma. The LLOQ of RKI-1447 in rat plasma was $10 \mathrm{ng} / \mathrm{mL}$, the precision was $12.7 \%$, and the accuracy was $86.4 \%$. The lowest limit of detection (LLOD) of RKI-1447 in rat plasma was $4 \mathrm{ng} / \mathrm{mL}$, and the signal-to-noise ratio was 3.

As shown in Table 1, intra-day and inter-day precision RSDs of RKI-1447 in plasma were lower than $11 \%$. The accuracy range was between $91.6 \%$ and $107.1 \%$, the average recovery was higher than $53.6 \%$, and the matrix effect was between $85.1 \%$ and $87.0 \%$.

None of the RKI-1447 showed any significant peak $(\geq 20 \%$ of the LLOQ and $5 \%$ of the IS,) in blank samples injected after the ULOQ samples. Adding 1.5 extra minutes to the end of the gradient elution effectively washed the system between samples, thereby eliminating carry-over $[11,12]$.

It was suggested that the stability of RKI-1447 in spiked samples placed at room temperature for $6 \mathrm{~h}$, processed and placed at room temperature for $12 \mathrm{~h}$, frozen-thawed 3 times, and placed at $-70{ }^{\circ} \mathrm{C}$ for 30 days was good, since the

Table 1. Accuracy, precision, matrix effect, and recovery of RKI-1447 in rat plasma

\begin{tabular}{|c|c|c|c|c|c|c|}
\hline \multirow[t]{2}{*}{ Concentration $(\mathrm{ng} / \mathrm{mL})$} & \multicolumn{2}{|c|}{ Accuracy $(\%)$} & \multicolumn{2}{|c|}{ Precision $\left(\mathrm{RSD}^{2} \%\right)$} & \multirow[t]{2}{*}{ Matrix effect $(\%)$} & \multirow[t]{2}{*}{ Recovery (\%) } \\
\hline & Intra-day & Inter-day & Intra-day & Inter-day & & \\
\hline 30 & 6.3 & 10.8 & 104.6 & 91.6 & $85.1 \pm 7.4$ & $62.8 \pm 5.5$ \\
\hline 450 & 7.3 & 9.2 & 95.5 & 104.8 & $87.0 \pm 2.4$ & $55.9 \pm 1.6$ \\
\hline 1800 & 4.7 & 5.7 & 107.1 & 95.3 & $86.4 \pm 0.8$ & $53.6 \pm 0.5$ \\
\hline
\end{tabular}




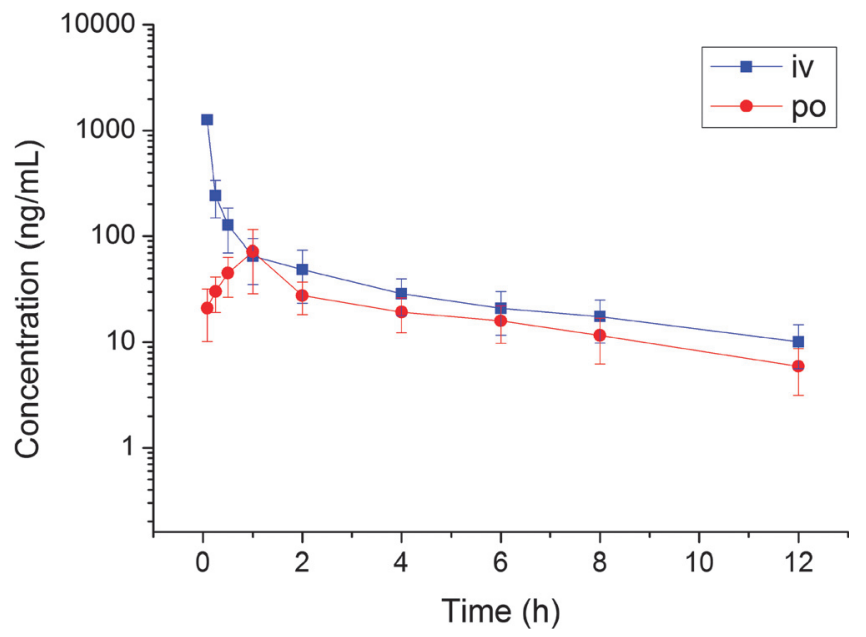

Figure 4. Plasma concentration-time curve of RKI-1447 after oral $(10 \mathrm{mg} / \mathrm{kg})$ and intravenous $(2 \mathrm{mg} / \mathrm{kg})$ administration

Table 2. Main pharmacokinetic parameters of RKI-1447 in rats

\begin{tabular}{lccc}
\hline Parameters & Unit & Intravenous $(2 \mathrm{mg} / \mathrm{kg})$ & Oral $(10 \mathrm{mg} / \mathrm{kg})$ \\
\hline $\mathrm{AUC}_{(0-t)}$ & $\mathrm{ng} / \mathrm{mL} * \mathrm{~h}$ & $615.5 \pm 107.9$ & $224.6 \pm 61.7$ \\
$\mathrm{AUC}_{(0-\infty)}$ & $\mathrm{ng} / \mathrm{mL} * \mathrm{~h}$ & $713.2 \pm 118.7$ & $316.0 \pm 109.3$ \\
$\mathrm{MRT}_{(0-t)}$ & $\mathrm{h}$ & $2.2 \pm 0.5$ & $3.5 \pm 0.4$ \\
$\mathrm{MRT}_{(0-\infty)}$ & $\mathrm{h}$ & $4.9 \pm 1.9$ & $8.8 \pm 6.3$ \\
$t_{1 / 2 z}$ & $\mathrm{~h}$ & $6.2 \pm 2.0$ & $7.0 \pm 5.9$ \\
$\mathrm{CL}_{\mathrm{z} / \mathrm{F}}$ & $\mathrm{L} / \mathrm{h} / \mathrm{kg}$ & $2.9 \pm 0.5$ & $35.1 \pm 12.1$ \\
$V_{\mathrm{z} / \mathrm{F}}$ & $\mathrm{L} / \mathrm{kg}$ & $25.8 \pm 9.7$ & $307.9 \pm 189.7$ \\
$C_{\max }$ & $\mathrm{ng} / \mathrm{mL}$ & $1272.4 \pm 130.1$ & $72.0 \pm 43.2$ \\
Bioavailability & \multicolumn{3}{c}{$7.3 \%$} \\
\hline
\end{tabular}

variation of RKI-1447 was within $\pm 14 \%$ and RSD was within $\pm 12 \%$.

Pharmacokinetics. Figure 4 displays the plasma concentration-time curves of RKI-1447 by PO and IV. Table 2 shows the main pharmacokinetic parameters analyzed by the non-compartment model. The bioavailability of RKI-1447 is relatively low $(7.3 \%)$, so the bioavailability could be further increased by improving dosage form. $T_{1 / 2 z}$ of RKI-1447 by IV and $\mathrm{PO}$ was $6.2 \pm 2.0 \mathrm{~h}$ and $7.0 \pm 5.9 \mathrm{~h}$, respectively, indicating fast drug metabolism.

\section{Conclusion}

In this study, we developed a fast UPLC-MS/MS method with good selectivity for RKI-1447 in rat plasma. The linear range was $10-2000 \mathrm{ng} / \mathrm{mL}$, and $50 \mu \mathrm{L}$ plasma was used and processed by the acetonitrile precipitation method. Compared to LC-MS/MS, the UPLC-MS/MS is more sensitive, possessing significant advantages in the investigation into the pharmacokinetics of drugs. This method was first applied to the investigation into the pharmacokinetics of RKI-1447 in rats, and the bioavailability was first reported to be $7.3 \%$.

Acknowledgements. This study was supported by grants from the incubator project of The First Affiliated Hospital of Wenzhou Medical University (FHY2014012 and FHY2014040).

\section{References}

1. Clark, E. A.; Golub, T. R.; Lander, E. S.; Hynes, R. O. Nature 2000 , 406, 532-535

2. Chen, M.; Knifley, T.; Subramanian, T.; Spielmann, H. P.; O'Connor, K. L. PLoS One 2014, 9, e89892.

3. Sturge, J.; Wienke, D.; Isacke, C. M. J. Cell Biol. 2006, 175, 337-347.

4. Patel, R. A.; Forinash, K. D.; Pireddu, R.; Sun, Y.; Sun, N.; Martin, M. P.; Schonbrunn, E.; Lawrence, N. J.; Sebti, S. M. Cancer Res. 2012, 72, 5025-5034.

5. Li, S. P.; Cheng, X. M.; Wang, C. H. J. Ethnopharmacol. 2017, 203, 127-162.

6. Cheng, H. S.; Ton, S. H.; Kadir, K. A. Phytochem. Rev. 2017, 16, 159-193.

7. Pang, H. Q.; Tang, Y. P.; Cao, Y. J.; Tan, Y. J.; Jin, Y.; Shi, X. Q.; Huang, S. L.; Sun, D. Z.; Sun, J.; Tang, Z. S.; Duan, J. A. J. Chromatogr. B: Anal. Technol. Biomed. Life Sci. 2017, 1061-1062, 372-381.

8. Wang, L.; Sang, M.; Liu, E.; Banahene, P. O.; Zhang, Y.; Wang, T.; Han, L.; Gao, X. J. Pharm. Biomed. Anal. 2017, 140, 45-61.

9. Wang, S.; Li, D.; Pi, J.; Li, W.; Zhang, B.; Qi, D.; Li, N.; Guo, P.; Liu, Z. J. Pharm. Pharmacol. 2017, 69, 1540-1551.

10. Zhang, X.; Liu, S.; Pi, Z.; Liu, Z.; Song, F. J. Chromatogr. B: Anal. Technol. Biomed. Life Sci. 2017, 1041-1042, 11-18.

11. Williams, J. S.; Donahue, S. H.; Gao, H.; Brummel, C. L. Bioanalysis 2012, 4, 1025-1037.

12. Wang, S.; Wu, H.; Huang, X.; Geng, P.; Wen, C.; Ma, J.; Zhou, Y.; Wang, X. J. Chromatogr. B: Anal. Technol. Biomed. Life Sci. 2015, 990, 118-124. 13. Ye, W.; Chen, R.; Sun, W.; Huang, C.; Lin, X.; Dong, Y.; Wen, C. Wang, X. J. Chromatogr. B: Anal. Technol. Biomed. Life Sci. 2017, 1060, $144-149$.

14. Ma, J. S.; Wang, S. H.; Huang, X. L.; Geng, P. W.; Wen, C. C.; Zhou, Y. F.;

Yu, L. S.; Wang, X. Q. J. Pharm. Biomed. Anal. 2015, 111, 131-137.

15. Lin, G. Y; Wu, H. Y; Wang, Z. B. Zhang, H. Y.; Chen, L. G; Wang, X. Q.

Hu, L. F.; Ma, J. S. Lat. Am. J. Pharm. 2011, 30, 1775-1779.

16. Ma, J. S.; Zhang, Y. Q.; Zhang, M. L.; Fan, X. F.; Wang, Z. B.; Shentu, Y. P.; Wang, Z. Y.; Wang, X. Q. Lat. Am. J. Pharm. 2011, 30, 613-618.

17. Yang, X. Z.; Hu, L. F.; Lin, G. Y.; Xu, R. A.; Zhang, Y.; Chen, L. Z.; Zhu, L. H.; Zhao, F.; Wang, X. Q. Lat. Am. J. Pharm. 2010, 29, 1038-1043.

18. Yu, X. M.; Xu, R. N.; Li, J. W.; Ma, J. S.; Deng, J.; Wang, X. Q. Lat. Am. J. Pharm. 2011, 30, 373-377.

19. Wang, X.; Wang, S.; Lin, F.; Zhang, Q.; Chen, H.; Wang, X.; Wen, C.; Ma, J.; Hu, L. J. Chromatogr. B: Anal. Technol. Biomed. Life Sci. 2015, 983-984, 125-131.

20. Wang, S. H.; Wu, H. Y.; Huang, X. L.; Geng, P. W.; Wen, C. C.; Ma, J. S.; Zhou, Y. F.; Wang, X. Q. J. Chromatogr. B: Anal. Technol. Biomed. Life Sci. 2015, 990, 118-124.

21. Zhang, Q.; Wen, C.; Xiang, Z.; Ma, J.; Wang, X. J. Pharm. Biomed. Anal. 2014, 90, 134-138.

22. Zheng, M.; Gu, S.; Chen, J.; Luo, Y.; Li, W.; Ni, J.; Li, Y.; Wang, Z. J. Chromatogr. B: Anal. Technol. Biomed. Life Sci. 2017, 1055-1056, 178-184. 